Causes of Academic Procrastination of Students Who Made Class

Repetition

\author{
Mehmet Kandemir*, Mehmet Palancı*, Tahsin İlhan ${ }^{* * *}$ \\ Müjdat Avcr ${ }^{* * *}$
}

Received date: $\mathbf{1 5 . 0 2 . 2 0 1 6}$

Accepted date:15.08.2017

\begin{abstract}
The purpose of the research is to test the academic procrastination behaviours of 1 st and 2nd grade high school students within the scope of a model with variables of self-recovery, life satisfaction, academic identification and motivation. The research that used the causal comparative method were carried out on 234 high school students who made a class repetition in the academic year of 2013-2014. 92 (40\%) of the students in the research group were male and $140(60 \%)$ of them were female students. As the tool for data collecting, Academic Procrastination Scale developed by Aitken (1982) and adopted into Turkish by Balkıs (2007), Self-Recovery Power Scale developed by Terzi (2006), Life Satisfaction Scale developed by Diener (2004) and adopted into Turkish by Köker (1991), Academic Motivation Scale developed by Bozanoğlu (2004), Academic Identification Scale developed by Balkıs, Duru and Buluş (2009) are used in the research. According to the research results, received fit coefficients related to final model are resulted highly above of acceptable limits. That the NFI, CFI, IFI and TLI values are above .90 indicates that this model adjusts well. Chi-square value was found as $\left(\mathrm{X}^{2}\right.$ /sd=3.33/2) 1.67 and RMSEA was found as .048. Also, motivation variable affects academic procrastination in a direct, meaningful and negative ways $(\mathrm{t}=-5.74, \mathrm{p}<.01)$. Motivation's direct affect value to the academic procrastination is found as $\beta=-.40$. Accordingly, it can be said that students' academic procrastination behaviours decrease along with improved motivation.
\end{abstract}

Keywords: Academic postponement, self-recovery, life satisfaction, academic identification and motivation

\footnotetext{
* Kırıkkale University Faculty of Education, Kırıkkale 71000, Turkey, mkandemir61@gmail.com

${ }^{* *}$ Karadeniz Technical University, Fatih Education Faculty, Trabzon 61000, Turkey, mehmetpalanci@arel.edu.tr

${ }^{* * *}$ Gaziosmanpaşa University, Faculty of Education, Tokat 70000, Turkey, tahsin.ilhan@gop.edu.tr

**** Dokuz Eylül University, Department of Sociology, İzmir 3522, Turkey, mujdatavci@deu.edu.tr
} 


\title{
Sınıf Tekrarı Yapan Öğrencilerin Akademik Erteleme Nedenleri
}

Doi numarası: 10.17556/erziefd.334989

\author{
Mehmet Kandemir*, Mehmet Palancı*, Tahsin İlhan ${ }^{* * *}$ \\ Müjdat Avcl****
}

Geliş tarihi: 15.02.2016

Kabul tarihi:15.08.2017

\section{Öz}

Araștırmanın amacı ise, sınıf tekrarı yapan lise 1 ve 2 . sınıf öğrencilerinin akademik erteleme davranışını, kendini toparlama, yaşam doyumu, akademik özdeşleşme ve motivasyon değişkenleriyle oluşturulan bir model kapsamında test etmektir. Nedensel karşılaştırmalı yönteminin kullanıldığı araştırmada, 2013-2014 eğitim öğretim yılında, sınıf tekrarı yapan 234 lise öğrencisi üzerinde yapılmıştır. Araştırma grubundaki öğrencilerin 92 (\%40)'si erkek ve 140 (\%60)'ı kız öğrencidir. Veri toplama aracı olarak; Aitken (1982) tarafından, geliştirilmiş, Balkıs (2007) tarafından Türkçeye uyarlanmış, Akademik Erteleme Ölçeği; Terzi (2006) tarafından geliştirilmiş Kendini Toparlama Gücü Ölçeği; Diener (2004) tarafından geliştirilen ve Köker (1991) tarafından Türkçe'ye uyarlanan Yaşam Doyumu Ölçeği; Bozanoğlu (2004) tarafından geliştirilen Akademik Güdülenme (Motivasyon) Ölçeği; Balkıs, Duru ve Buluş (2009) tarafından geliştirilmiş Akademik Özdeşleşme Ölçeği araştırmada kullanılmıştır. Araştırma sonuçlarına göre, nihai modele ilişkin elde edilen uyum katsayıları kabul edilen sınırların oldukça üzerinde çıkmıştır. NFI, CFI, GFI, IFI, TLI' nın .90'ın üzerinde çıkması o modelin iyi uyum gösterdiğini işaret etmektedir. Ki-Kare (X²/sd=3.33/2) 1.67 ve RMSEA .048 bulunmuştur. Aynı zamanda, motivasyon değişkeninin akademik ertelemeye doğrudan, anlamlı ve negatif yönlü etki yaptığı görülmektedir $(\mathrm{t}=-5.74, \mathrm{p}<.01)$. Motivasyonun akademik ertelemeye doğrudan etki değeri $\beta=-$ .40 olduğu görülmektedir. Buna göre, öğrencilerin motivasyonun artması ile birlikte, akademik erteleme davranışlarının azaldığını söylenebilir.

Anahtar kelimeler: Akademik erteleme, kendini toparlama, yaşam doyumu, akademik özdeşleşme ve motivasyon

\footnotetext{
* Kırıkkale University Faculty of Education, Kırıkkale 71000, Turkey, mkandemir61@gmail.com

${ }^{* *}$ Karadeniz Technical University, Fatih Education Faculty, Trabzon 61000, Turkey, mehmetpalanci@arel.edu.tr

*** Gaziosmanpaşa University, Faculty of Education, Tokat 70000, Turkey, tahsin.ilhan@gop.edu.tr

**** Dokuz Eylül University, Department of Sociology, İzmir 3522, Turkey, mujdatavci@deu.edu.tr
} 


\section{Giriş}

Öğrencilerin eğitim yaşam süresini etkileyen önemli faktörlerden biri olan sınıf tekrarı, eğitim sisteminin önemli bir olgusudur. Bir öğrencinin sınıf tekrarı yaşaması, başarısızlık kimliği yaşaması, akranlarına göre yaşama en az 1 yll geriden devam etmesi, değişen duruma uyum sağlayamaması gibi istenmeyen yaşantılara neden olabilmektedir. Öğrencilerin başarısızlık yaşayarak, bu olgunun içine girmesine neden olabilecek önemli değişkenler arasında öğrencilerin yaygın olarak yaptığı akademik erteleme davranışı gösterilebilir. Bu davranış, Rothblum, Solomon ve Murakami (1986) tarafından sınavlara hazırlanma, ödevleri geciktirme gibi akademik görevleri, sürekli ya da bazen geciktirme tanımlanmaktadır. $\mathrm{Bu}$ tanılama, akademik ertelemeyle ilgili yapılan ilk tanımlamalardandır. Akademik ertelemeyle ilgili yapılan tanımlamaların daha sonra, öğrencilerin yaşadığı, içsel ya da dışsal davranışlarıyla ve davranışın sonuçlarıyla ilişkilendirildiği görülmektedir. Senecal, Koestner ve Vallerand (1995), akademik erteleme davranışını, öğrencilerin kendilerinden beklenen akademik görevlerini zamanında yapmamış olmasına bağlı olarak, stres düzeyinin üst seviyesine çıııncaya kadar bu görevlerinden uzak durma olarak tanımlamaktadır. Ferrari, Johnson ve McCown (1995) göre ise akademik erteleme davranışı, öğrencilerin akademik başarısızlık yaşamasına neden olan akademik görevlerden kaçınma davranışı olarak değerlendirmektedir. Akademik erteleme ile ilgili hangi tanım yapılırsa yapılsın, öğrencilerin akademik görevlerini geciktirmesine ve buna bağlı olarak ertelemenin negatif sonuçlarına vurgu yapıldığı görülmektedir. Diğer taraftan, öğrenciler akademik erteleme yaparak (Tice \& Baumeister, 1997) kısa süreli bazı faydalar elde edebilmektedirler. Başka bir anlatımla, öğrenciler erteleme davranışı yaparak, ders çalışma, sınava hazırlanma gibi yaşadıkları akademik kaygılardan belli sürekliğine kurtulmaktadırlar. Kandemir (2012) tarafından bir araştırmada, üniversiteye giriş sınavlarına hazırlanan öğrencilerin yaşadıkları başarısızlık korkusu ve sınav kaygısı ile akademik erteleme arasında olumlu yönde ilişkili olduğu bulunmuştur. Bu bağlamda düşünüldüğünde, öğrenciler yaşadıkları korku ve kaygıdan uzaklaşmanın bir yöntemi olarak erteleme yaptığı, yani öğrenciler akademik erteleme davranışı ile kısa süreli rahatlamalar yaşadıkları söylenebilir.

Akademik erteleme davranışı, ertelemenin en sık yaşanılan türü olduğu bilinmektedir (Balkıs, 2006; Clark \&Hill, 1994). Hill, Chabot ve Barral (1978) göre, üniversite öğrencilerinin yaklaşık \%50'si; Solomon ve Rothblum'a (1984) göre, yaklaşık \% 46'sı, Balkıs ve Duru'ya (2009) göre, yaklaşık olarak \% 23' ü akademik erteleme yapmaktadır. Literatürde akademik ertelemeye yönelik belirtilen rakamlar, bu davranışın yaygın olduğunu göstermektedir. Akademik erteleme yapan öğrenciler, bu davranışın olumsuz sonuçlarıyla karşılaştıklarına ilişkin önemli çalışmalar bulunmaktadır (Burka \& Yuen, 1983; Kandemir, 2010). Akademik erteleme davranışı, erteleme yapan öğrencinin akademik başarısızlık yaşaması (Burka \& Yuen, 1983; Ferrari, Johnson ve McCown, 1995; Knaus, 1998), zor derslerden geri kalması (Rothblum, Solomon \& Murakami, 1986), okul devamsızlığı yapması ve okulu bırakması (Knaus, 1998) gibi olumsuz sonuçlar doğurmaktadır. Aynı zamanda, erteleme kişinin sağlığını olumsuz yönde etkilemektedir. Tice ve Baumeister (1997) üniversite öğrencileri ile yapmış oldukları araştırmada eğitim-öğretim yılının başında erteleme yapanlarla yapmayanların sağlık durumlarının benzerlik gösterdiğini ancak yıl sonunda erteleme yapan kişilerin daha fazla stres tepkisi gösterdiğini ortaya çıkarmıştır. Burka ve Yuen'a (1983) göre ise, bireyler erteleme davranışı yaptıklarını fark ettiklerinde suçluluk, panik, gerginlik, kaygı, sıkıntı ve yetersizlik gibi olumsuz duygular yaşamaktadırlar. Knaus 
(1998), erteleme yapan bireylerin yaşadıkları duygusal sonuçlarının çoğunun, bilişsel nedenlere bağlı olarak açıklanmakta ve bu iki yön arasında bir döngü oluştuğunu söylemektedir.

Akademik ertelemenin, yaygınlığı ve sonuçlarının yanında akademik ertelemenin nedensellikleri üzerinde önemli çalışmaların olduğu literatürde görülmektedir (Farran, 2004; Kandemir, 2010; Klassen, Krawchuk \& Rajani, 2007). Akademik ertelemenin nedensellik araştırmalarında, benlik, özyeterlik, kişilik, motivasyon, yaşam doyumu, zaman yönetimi, kontrol odağı gibi önemli değişkenler olduğu görülmektedir (Kandemir, 2012). Aynı zamanda, akademik ertelemenin bir güdülenme ya da motivasyon sorunu olduğunu açılkayan önemli literatür bulunmaktadır (Klassen ve diğ.,2008; Lekich, 2006). Bozanoğlu'na (2004) göre, akademik güdülenme en temel anlamıyla akademik işler için gerekli enerjinin üretilmesi olarak tanımlanmaktadır. Burka ve Yuen (1983), güdülenme ve erteleme arasındaki döngüyü şu şekilde açıklamaktadır: Bireyler, başarı için güdülenmenin önemli olduğunu bilmekte ve erteleme döngüsü sürecinde bu durumun bilincinde olarak işlerin başlangıcında güdülerini daha yüksek tutacaklarına dair kendilerine sözler vermektedirler. Ancak, bu bireyler istenilen süre içerisinde akademik etkinliklerini yerine getirmek için niyetli olmalarına rağmen kendi kendilerini güdüleme konusunda zaman zaman başarısız olabilmektedirler (Senecal, Koestner \& Vallerand 1995). Dolayısıyla, var olan bu durum bireylerin erteleme davranışının ortaya çıkmasına neden olmaktadır. Araştırmanın diğer bir değişkeni olan yaşam doyumunun da akademik ertelemenin önemli bir değişkeni olduğu ilgili literatürde görülmektedir (Binder, 2000; Savithri, 2014). Veenhoven (1996) yaşam doyumu, bireyin kendi yaşantısından ne kadar hoşnut olduğunun göstergesi olarak yaşam doyumunu tanımlamaktadır. Binder (2000) ve Savithri (2014) öğrencilerin yaşamından almış oldukları doyum ile akademik erteleme arasında negatif yönlü bir korelasyon olduğunu, aynı zamanda yaşam doyumunun akademik ertelemeyi yordamada negatif yönlü ve anlamlı bir etkisinin olduğunu ifade etmektedirler. Öğrencinin okul yaşamında önemli bir değişken olan diğer bir değişken de, akademik özdeşleşmedir. Akademik özdeşleşme, öğrencinin akademik ortamda göstermiş olduğu akademik performansı üzerine temellendirdiği benlik saygısının bir devamıdır (Osborne, 1997). Motivasyon kavramıyla yüksek bir korelasyona da sahip olan akademik özdeşleşme, Balkıs, Duru ve Buluş’a (2009) göre akademik ertelemeyle negatif yönlü ve güçlü bir ilişki içindir. Öğrencilerin kendini akademik görevlerle ilişkilendirmesi, bu görevlerin kendi benliğine katkı sağladığını görmesi, akademik sorumluluklarını ertelemeden yerine getirmeye neden olabilir. Son yıllarda, bireylerin günlük yaşamda karşılaştıkları problemlerle etkili bir şekilde başa çıkma yeteneği olarak tanımlanan kendini toparlama (yılmazlık) (Allen \& Hurtes, 1999), insan doğasını açıklamada kullanılan önemli bir değişkendir. Bu değişkenle akademik erteleme arasında ilişkiyi açıklamaya çalışan önemli araştırmalar bulunmaktadır. İlgili literatür incelendiğinde, kendini toparlama gücü akademik erteleme arasında negatif yönlü güçlü ilişkilerin olduğu görülmektedir (Öksüz ve Güven, 2014) .

Akademik erteleme davranışını açıklamaya yönelik yapılan araştırmalarda yukarıda belirtildiği gibi, kendini toparlama, yaşam doyumu, motvasyon, akademik güdülenme değişkenleri önemli yer tutmuştur. Literatür incelendiğinde, sınıf tekrarı yapan öğrencilerin yani akademik risk grubu özelliğini taşıyan öğrencilerin akademik erteleme davranışını açıklamayla ilgili kendini toparlama, yaşam doyumu, motivasyon, akademik güdülenme değişkenlerinin kullanılmadığı ya da birlikte, akademik ertelemeyi ne düzeyde açıkladığına ilişkin araştırmalara literatürde 
rastlanmamıștır. Bu bağlamda düşünüldüğünde, yapılan bu araștırmanın katma değerinin önemli olduğu düşünülmüştür. Araştırmanın bir model testiyle yürütülüyor olması bu değişkenlerin birlikte kullanıldığı araştırmalardan farklılı̆̆ı olduğu söylenebilir.

Sınıf tekrarı yapan lise öğrencilerinin akademik erteleme davranışı kendini toparlama, yaşam doyumu, akademik özdeşleşme ve motivasyon değişkenleriyle doğrudan ve dolaylı ilişkilerle bir model kapsamında yordanmakta mıdır? Bu araştırma sorusuna yönelik, kuramsal ilişkiler dikkate alınarak oluşturulan hipotez test modeli aşağıdaki gibidir.

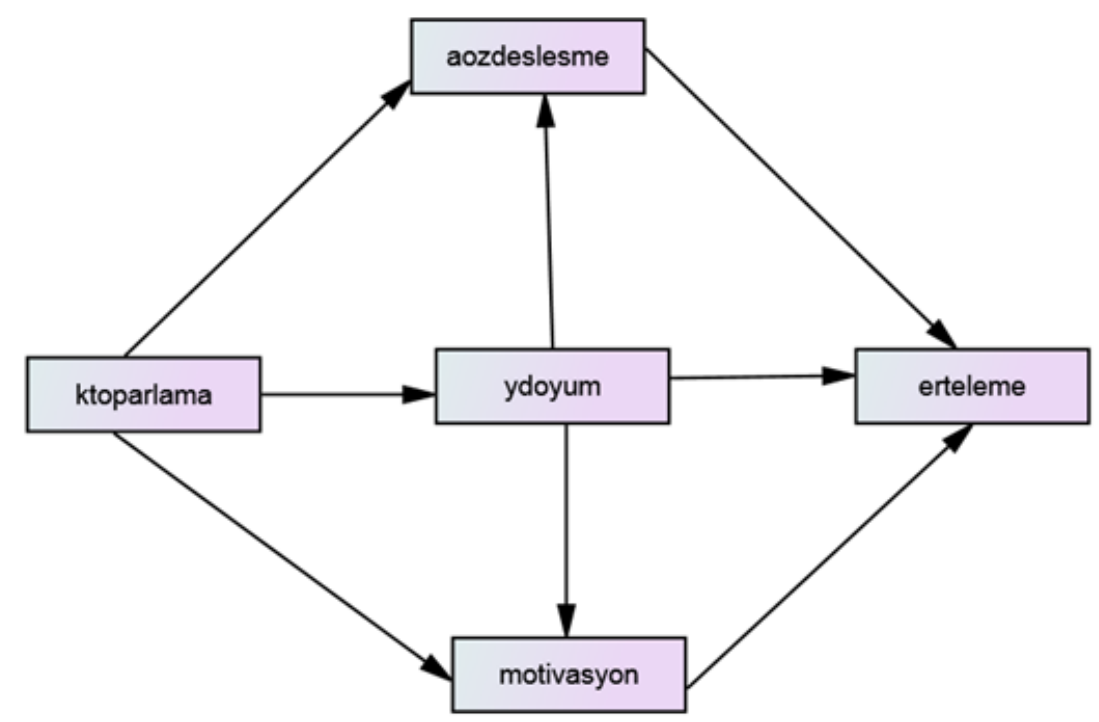

\section{Hipotezler}

1. Akademik erteleme davranışı, kendini toparlama, yaşam doyumu, akademik motivasyon ve akademik özdeşleşme ile bir model kapsamında yordanmaktadır.

2. Akademik erteleme davranışı; yaşam doyumu, motivasyon ve akademik özdeşleşme değişkenleri tarafından doğrudan etkilerle yordanmaktadır.

3. Kendini toparlama davranışı diğer değişkenlerle birlikte toplam etkisi, akademik ertelemeyi yordamaktadır.

4. Yaşam doyumu, diğer değişkenlerle (motivasyon ve akademik özdeşleşme) birlikte toplam etkisi, akademik ertelemeyi yordamaktadır.

\section{Yöntem}

$\mathrm{Bu}$ bölümde araştırma sorularına cevap aranması için benimsenen yol anlaşılır olarak sergilenmelidir. Bunun için araştırmanın türüne göre değişiklikler yapılabilmek koşuluyla aşağıdaki alt başlıklar açıklanmalıdır. Araştırmanın deseni araştırma soruları ve süreç ile bağlantılı olacak şekilde verilmeli, veri toplama araçlarının psikometrik özellikleri tanıtılmalıdır. Verilerin analizi için veri üzerinde yapılan çalışmalar ve analiz tekniğine karar verme süreci gerekli ise yapılan analizi kısa tanıtımı yapılmalıdır. 


\subsection{Araştırmanın Modeli/ Deseni}

Nedensel-karşılaştırmalı modele göre (Fraenkel ve Norman, 2006; Gall, Borg ve Gall 1996) var olan bir durum içinde araştırmanın müdahalesi olmadan değişkenler arasındaki ilişkiler nedensonuç etki bağlamında incelenmektedir. Araştırmada, üniversite öğrencilerinin akademik erteleme davranışlarını, kendini toparlama, güdülenme, yaşam doyumu ve akademik özdeşleşmeyle birlikte açıklanmaya çalışıldığı bir hipotez model önerilmiştir. Bu modelin test edilmesi için path analizi çalışması yapılmıştır. Path analizi, yapısal eşitlik modelleri veya AMOS"da ölçülen ve gizil değişkenler arasındaki "nedensel" ilişkileri sınamada kullanılan kapsamlı bir istatistiksel yaklaşımdır. Bu araştırma kapsamında oluşturulan kavramsal modelde değişkenler arasında tek yönlü oklarla gösterilen her bir yol, bir neden-sonuç ilişkisi ortaya koymaktadır. Karasar (2002) tarama modeli ile elde edilen bilgilerin gerçek bir neden-sonuç ilişkisi olarak yorumlanamayacağını belirtmekle birlikte, araştırmaların yapılmasındaki karşılaşılan ekonomik, teknik veya etik güçlükler nedeniyle, tarama ile bulunan ilişkilerin de neden-sonuç ilişkisi olarak yorumlanabileceğini belirtmiştir. Bu anlamda bu araştırmada ortaya konulan hipotez modelin test edilmesi için nedensel karşılaştırmalı model kullanılmıştır.

\section{2. Çalışma Grubu}

Araştırma, 2013-2014 eğitim öğretim yılında, 234 öğrenci üzerinde yapılmıştır. Araştırma grubundaki öğrenciler, 1 yıl sınıfta kalmış öğrenciler olup, 2013-2014 eğitim öğretim yılında aynı sınıfta okula devam eden öğrencilerdir. Araştırmaya katılan öğrencilerin 92 (\%40)'si erkek ve 140 (\%60)'ı kız öğrencidir.

\subsection{Verilerin Toplanması}

\subsubsection{Veri toplama araçları}

Aitken Akademik Erteleme Ölçeği: Aitken (1982) tarafından geliştirilmiş ölçek Balkıs (2007) tarafından Türkçeye uyarlanmıştır. Ölçek tek boyutludur ve 5'li likert tipi toplam 16 maddeden oluşmaktadır. Balkıs (2007) tarafından yapılan uyarlama çalışmalarında, ölçeğin geçerlik çalışmaları için, farklı bölümlerde öğrenim gören, 293 öğrenciye ulaşılmıştır. Ölçekteki her maddenin akademik görevleri erteleme eğilimi düzeyini ölçüp ölçmediğini ayırt etmek için madde toplam (item-total) korelasyonlarına bakıldığında, .33 ile .73 arasında bir değişim olduğu görülmüştür. Ölçeğin iç tutarlık katsayısı Cronbach Alfa $(\alpha)=.89$ olarak görülmüştür Testtekrar test güvenirliği için yapılan analizlerde Pearson korelasyon katsayısı $r=.87, p<.001$ düzeyinde anlamlı bulunmuştur. Ölçeğin yapı geçerliliğini test etmek için faktör analizi yapılmıştır. Faktör Analizi sonucunda ölçeğin tek faktörlü bir yapıya sahip olduğu belirlenmiştir. Tek faktörün açıkladığı varyans \% 38 ve bu faktöre ait öz değer 6.14'tür.

Akademik Güdülenme Ölçeği: Bozanoğlu (2004) tarafında geliştirilen akademik güdülenme ölçeği, öğrencilerin akademik güdülenme düzeylerindeki bireysel farklılıkların belirlenmesinde kullanılabilmesi amacıyla geliştirilmiştir. 20 maddeden oluşan ölçeğin, faktör analizleri sonucunda toplam değişkenliğin \% 42.2'sini açıklayan üç faktör elde edilmiştir. Madde-toplam korelasyon değerleri .43 ile .60 arasında değişen ölçeğin iç tutarlık katsayısı ölçeğin bütünü için .86 olarak bulunmuştur. 
Yaşam Doyumu Ölçeği (The Satisfaction with Life Scale): Diener, Emmons, Larsen ve Griffin (1985) tarafından geliştirilmiş olup genel yaşam doyumunu ölçmektedir. Ölçek farklı yaş gruplarında ve farklı örgütlerdeki uygulamalarda kullanılabilmektedir. Life Satisfaction Index-A ile $r=.81$, akranların değerlendirmeleri ile $r=.64$ korelasyonu olan Yaşam Doyumu Ölçeği"nin oldukça yüksek paralel test geçerliliği belirlenmiştir Test-tekrar test güvenirliği iki hafta ve bir ay sonraki ölçümlerde .84 olarak bulunmuştur (Pavot ve Diener, 2009). Pavot ve Diener (2009) ölçeğin kullanımının serbest olduğunu ve izin alınmasına gerek olmadığını belirtmişlerdir. Ölçek daha önce Köker (1991) tarafından Türkçe"ye çevrilmiştir. Araştırmacı tarafından tekrar Türkçe"ye çevrilen ölçek, toplam beş maddeden oluşmaktadır. 1-7 dereceli Likert tipindedir. Cronbach alpha güvenirlik katsayısı .87 olarak hesaplanmıştır.

Kendini Toparlama Gücü Ölçeği: Terzi (2006) tarafından geliştirilmiş kendinin toparlama gücü ölçeği, Ölçek 24 maddeli 7'li Likert tipi bir ölçektir. Ölçeğin yapı geçerliği faktör analizi ile saptanmıștır. Yapılan benzer ölçekler geçerliği çalışmasında ise KTGÖ ile Genelleștirilmiş Özyeterlik Ölçeği arasında anlamlı bir ilişki bulunmuştur ( $r=.83$ ). Ölçeğin cronbach alpha güvenirlik katsayısı .82; test-tekrar test güvenirlik katsayısı $r=.84$ olarak saptanmıştır. Ölçeğin madde toplam korelasyonları ise .03 ile .69 arasında bulunmuştur.

Akademik Özdeșleșme Ölçeği: Osborne (1997) tarafından geliştirilen akademik özdeşleşme ölçeği, Balkıs, Duru ve Buluş (2009) tarafından Türkçe'ye uyarlanmıştır. Orijinal ölçekte 13 madde yer almaktadır ve Chronbach alfa katsayısı .83. Uyarlama çalışması kapsamında yapılan analizlerde 7. Ve 10 maddenin madde toplam korelasyon katsayıları çok düşük olduğu için ölçekten çıkarılmıştır. Böylelikle ölçeğin Türkçe versiyonu 11 maddeden oluşmaktadır. 11 maddelik ölçeğin Cronbach alfa katsayısı .75, toplam varyansın \%32. 13'ünü açıklayan tek faktörden oluşmaktadır.

\subsection{Verilerin Analizi}

Sınıf tekrarı yapan lise öğrencilerinin akademik erteleme davranışı kendini toparlama, yaşam doyumu, akademik özdeşleşme ve motivasyon değişkenleriyle doğrudan ve dolaylı ilişkilerle bir model kapsamında yordanmaya çalışılmıştır. Bu amaçla, path (yol analizi) ve bu modelin test edilmesi için AMOS 16 istatistik programı kullanılmıştır. Path modelleri, gözlenen değişkenler arasındaki daha karmaşık ilişkilerin modellenmesi daha fazla katkı sağlanması için, regresyon analizini ve korelasyon katsayılarını kullanan bir anlayışa sahiptir. Path analizi, değişkenler arasında neden-sonuç ilişkisine dayalı modelleri kurar ve kurulan model, gözlenen korelasyonlara uygun açıklama getirmek ve bir dişsal değişkenin modelde yer alan diğer bir değişken ile arasındaki korelasyonu ve nedensellik etkisini ne ölçüde yansıttığını değerlendirmek amacıyla kullanılmaktadır (Bolen, 1989; Schumacker \& Lomax, 2004). Maruyama (1998) path analizini bağımlı değişkenler üzerindeki bağımsız değişkenlerin kısmi etkilerini standartlaştırılmış regresyon katsayıları ile gösteren bir analiz yöntemi olarak da bilinmektedir. Path analizinde aynı zamanda, toplam, doğrudan ve dolaylı etkiler içindeki herhangi iki değişken arasındaki toplam etkilerin ayrıştırılmasına katkılar sağlar (Bollen, 1989). Bu bağlamda, akademik erteleme davranışını, kendini toparlama, yaşam doyumu, motivasyon ve akademik özdeșleşme değişkenleri arasındaki doğrudan ve dolaylı ilişkilerle ne düzeyde yordandığını öğrenmek amacıyla Path modeli araştırmada kullanılmıştır. Hipotez modeli test 
etmeden önce veriler analize hazırlandı ve yapılması gereken bazı sayıtlılar yerine getirildi. Yapılan bu işlemler şu şekilde özetlenebilir: Araștırma verisinde yer alabilecek ve araştırma sonucunu etkileyebilecek olası aykırı ve uç değerler öncelikle tespit edilmeye çalışılmıştır. SPSS 19 paket programına girilen 234 öğrenciye ait verilerin, frekans dağılımları incelenmiştir. İnceleme sonucunda, 3 maddede, belirlenen ranjın dışına çıkılarak, 12, 22 ve 65 değerlerinin veri setine girildiği görülmüştür. İlgili anketler gözden geçirilerek gerekli düzeltmeler veri setinde yapılmıştır. Daha sonra, her bir öğrencinin Mahalanobis uzaklıklarına bakılmış, 0.05 anlamlılık düzeyi için ilgili regresyon modelindeki bağımsız değişken sayısına karşılık gelen chi square tablo değerinin üzerinde olan, Mahalanobis değerine sahip olan 2 öğrenciye ait veriler (veri numarası;91, 121), veri dosyasından çıkartılmıştır. Hem bu yöntemle hem de her bir öğrencinin $\mathrm{Z}$ değerlerine bakılarak (+3 ve -3 aralığı dışında kalan) 2 veriye ait uç değerler (outliers) temizlenmiş ve veri dosyası yeniden kaydedilmiştir. Uç değerler silinmeden önce akademik ertelemeyle ile ilgili normallik grafiği ve histogramı (Şekil 1 ve 2) incelenmiștir.

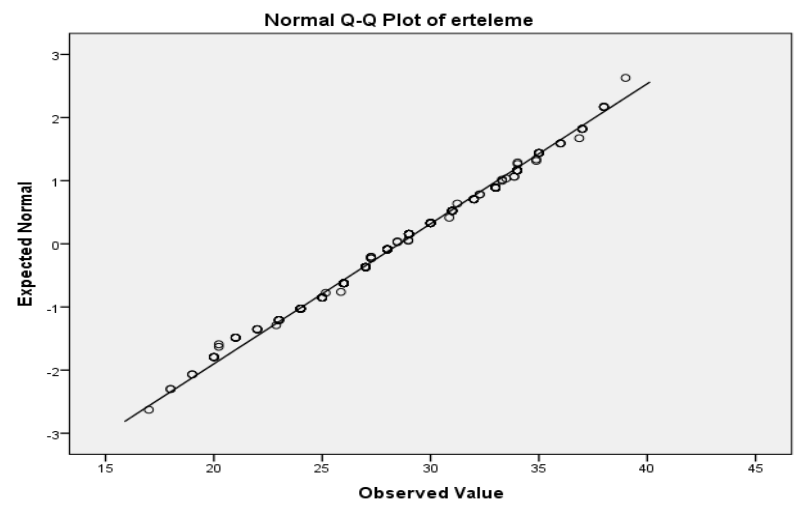

Şekil 2. Akademik ertelemenin normal dağılıma uygunluğuna ilişkin Q-Q grafiği

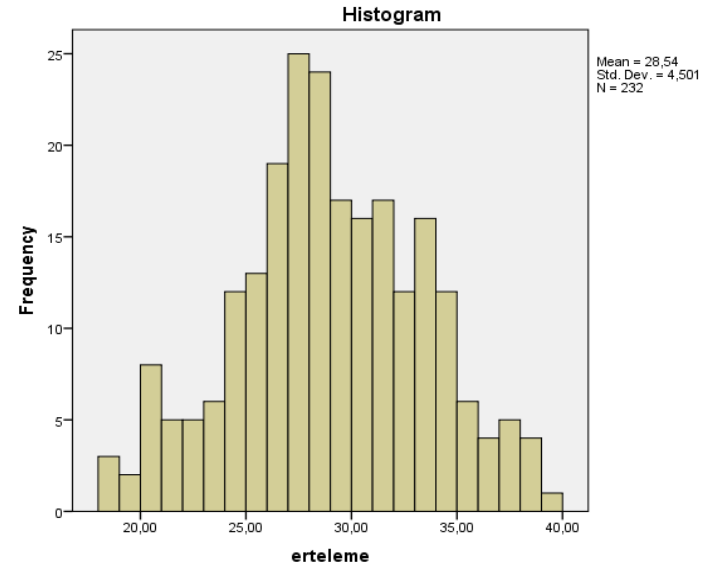

Şekil 3. Akademik erteleme puanına ilişkin histogram

Yukarıdaki incelemeler sonrasında yapılan düzenlemeler sonrasında, veride gerek tek boyutlu(univairate) gerekse çok boyutlu olarak (multivariate) uç ve aykırı değerin olmadığı sonucuna ulaşılmıştır. Tabachnick ve Fidell (2001)'e göre, regresyon analizinin ön koşullarından biri, yordanan ve yordayıcı değişkenlerin birbirleriyle doğrusal bir ilişki içinde olmasıdır. Bunun için öncelikle matriks saçılım grafikleri ve parçalı saçılım grafikleri yoluyla akademik öz yeterlik puanlarının bağımsız değişkenlerle ilişkilerini görselleştiren parçalı regresyon grafikleri incelenmiş ve sonucunda doğrusallığı etkileyecek bir durumun olmadığı görülmüştür. 
Doğrusallık için daha sonra, araştırma değişkenlerinin kendi aralarındaki ilişkileri incelenmiştir. Bu inceleme korelasyon analizinde .01 ve .05 anlamlılık düzeyinde gerçekleşmiştir. Sonuçlar Tablo 1'de sunulduğu gibidir.

Tablo 1

Araştırma Değişkenleri Arasındaki Korelasyonel İlişskiler

\begin{tabular}{lllllc}
\hline & 1 & 2 & 3 & 4 & 5 \\
\hline Akademik Erteleme (1) & 1 & & & & \\
Kendini Toparlama (2) & $-.38^{* *}$ & 1 & & & \\
Yaşam doyumu (3) & $-.26^{* *}$ & $.43^{* *}$ & 1 & & \\
Motivasyon (4) & $-.48^{* *}$ & $.48^{* *}$ & $.26^{* *}$ & 1 & \\
Akademik Özdeşleşme (5) & $-.22^{* *}$ & $.14^{*}$ & $.13^{*}$ & $.13^{*}$ & 1 \\
TOPLAM & 232 & 232 & 232 & 232 & 232 \\
\hline${ }^{*} \mathrm{p}<.05,{ }^{* *} \mathrm{p}<.01$ & & & & &
\end{tabular}

Tablo 1 incelendiğinde, araştırma değişkenleri arasında genel anlamda .01 ve .05 düzeyinde anlamlı ilişkilerin olduğu görülmektedir. Araştırmanın bağımlı değişkeni olan akademik erteleme ile bağımsız değişkenler arasında anlamlı ilişkinin olduğu görülmektedir. Korelasyon tablosu incelendiğinde, akademik erteleme davranışı ile diğer değişkenler arasında, negatif yönlü anlamlı ilişkilerin olduğu görülmektedir. Bu değişkelerden özellikle, motivasyon (-.48) ve kendini toparlama (-.38) değişkenlerinin güçlü ilişkisi olduğu bulunmuştur. Yordayıcı değişkenlerin ikisi arasında mükemmele yakın bir ilişki olduğunda birlikte değişkenliğe, ikiden çok yordayan değişken arasında mükemmele yakın bir ilişki olduğunda ise çoklu değişkenliğe işaret eder. Bağımsız değişkenler arasında .80 üzerindeki korelasyon çoklu bağlantı sorunun göstergesidir (Çokluk, Şekercioğlu ve Büyüköztürk, 2012). İkili ve çoklu değişkenliğin olup olmadığını anlamak için, korelasyon analiz sonucunu gösteren tablo yeniden incelenmiştir. Tablo 1 de incelendiğinde, değişkenler arasında 80 üzeri bir korelasyon katsayısı olmadığından değişkenler arasında çoklu değişkenlik sorununun olmadığını söylemek mümkündür.

Path analizinden önce, tek ve çok boyutlu durumlar için bağımlı değişkenin normalliğine de bakılmıştır. Bunun için, öğrencilerin akademik erteleme inancına yönelik puanların dağılımı ve histogramı incelenmiştir. Şekil 3 ve 4'de görüldüğü gibi, dağılımın normale yakın olduğu bulunmuştur. Kolmogorov-Smirnow testi sonucu incelendiğinde, öğrencilerin akademik erteleme puanlarını tek boyutlu düzeyde $\mathrm{p}=.10$ olduğu yani $\mathrm{p}>05$ olduğu, dolayısıyla puanların normal dağılım gösterdiği söylenebilir. Normallik testi için yapılan diğer bir analiz ise, ShapiroWilk testi sonucunun ise, $\mathrm{p}=.15$ olduğu yani $\mathrm{p}>05$ olduğu bulunmuştur. Bu sonuca göre de, akademik erteleme inancı puanlarının normal dağılım gösterdiği sonucuna ulaşmak mümkündür. Bu işlemlerden sonra, standartlaştırılmış hatalara yönelik istatistikler yapılmış ve uç değerlerin olup olmadığı yeniden gözden geçirilmiştir. Şekil 3’ de dağılımlar incelendiğinde, dağılımda, sağ ya da sola çarpıklığın olmadığı görülmektedir. Aynı zamanda, tahmin edilen değerlerin (predicted values) hata varyanslarının homojen olmasıdır. Bunun için, ZRESID'in ZPRED ile saçılım diyagramı incelenmiş, belirgin bir yapı göze çarpmamaktadır. Buna göre varyansların homojenliğinin sağlandığı söylenebilir. Bu bağlamda yapılan analiz sonrasında aşağıdaki gibi, histogram, grafik ve diyagrama ulaşılmıștır. Așağıdaki şekiller incelendiğinde, hataların normalliğinin de sağlandığı görülmektedir. 


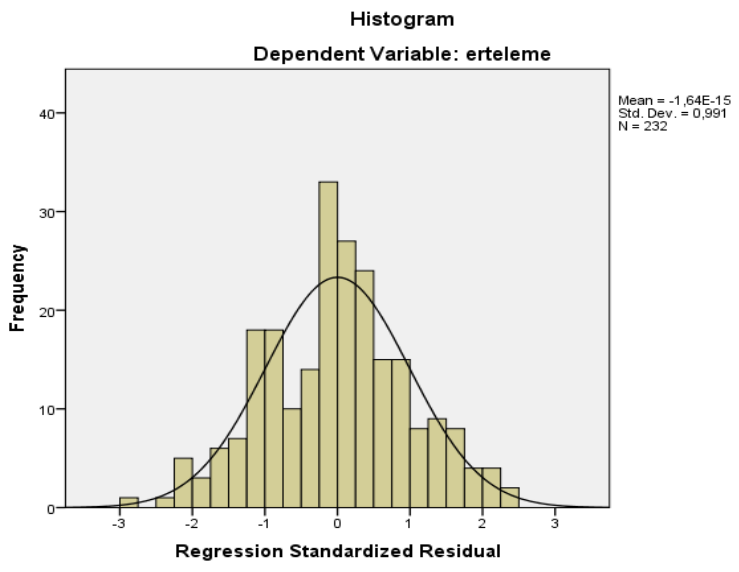

Şekil 4. Akademik Erteleme Puanlarının Standartlaştırılmış Puanlar Histogramı

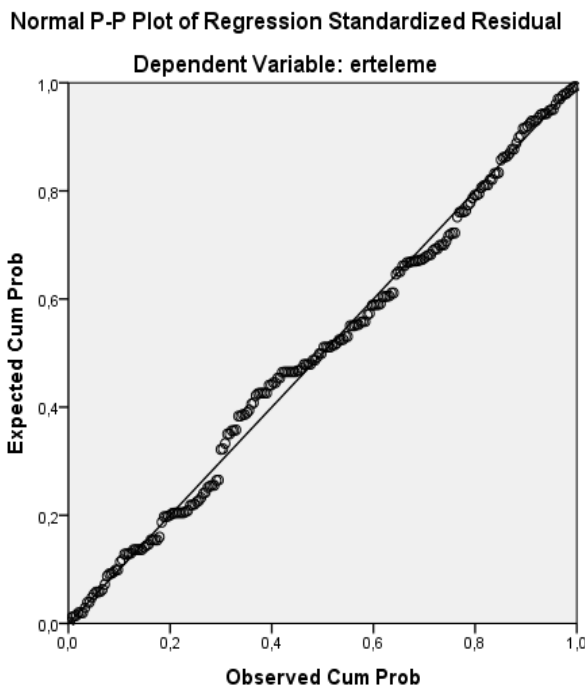

Şekil 5. Akademik Erteleme Puanlarının Normal P-P Grafiği

\section{Bulgular}

Akademik erteleme davranışının bir modelle açıklanmaya çalışıldığı araştırmada, verilerin düzenlemesi ve temel sayıtlıların sağlanmasından sonra, hipotez modelin AMOS 16 istatistik programında test edilmesi işlemine geçilmiştir. Yapılan analiz sonucunda, şu sonuçlara ulaşılmıştır. 


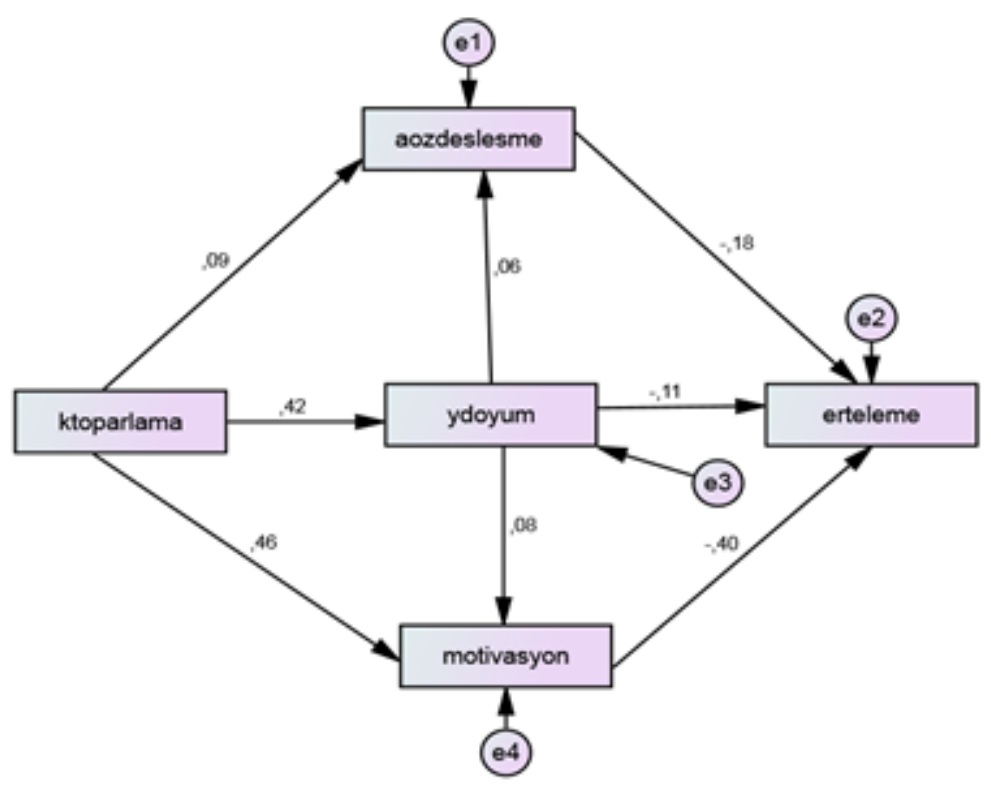

Şekil 6. Test edilmiş nihai model sonuçları

Tablo 2

Uyum Katsayılarına İlişskin İstatistiksel Değerler

\begin{tabular}{cccc}
\hline Ölçüm & İyi Uyum & Kabul Edilebilir Uyum & Modelin Uyum İndeksi Değerleri \\
\hline$\left(\mathrm{X}^{2} / \mathrm{sd}\right)$ & $\leq 3$ & $\leq 4-5$ & 1.67 \\
$\mathrm{RMSEA}$ & $\leq .05$ & $.06-.08$ & .048 \\
$\mathrm{NFI}$ & $\geq .95$ & $.94-.90$ & .97 \\
$\mathrm{CFI}$ & $\geq .97$ & $\geq .95$ & .98 \\
$\mathrm{GFI}$ & $\geq .90$ & $.89-.85$ & .95 \\
$\mathrm{TLI}$ & $\geq .95$ & $.94-.90$ & .95 \\
$\mathrm{IFI}$ & $\geq .95$ & $.94-.90$ & .99 \\
\hline
\end{tabular}

Nihai modele ilişkin elde edilen uyum katsayıları kabul edilen sınırların oldukça üzerinde çıkmıştır. NFI, CFI, GFI, IFI, TLI' nın .90'ın üzerinde çıkması o modelin iyi uyum gösterdiğini işaret etmektedir. Ki-Kare ( $\left.\mathrm{X}^{2} / \mathrm{sd}=3.33 / 2\right) 1.67$ ve RMSEA .048 bulunmuştur. Bu katsayllar ve uyum indeksleri dikkate alındığında, modelin istenen düzeyde uyum değerlerine sahip olduğu anlaşılmaktadır (Bollen, 1989; Browne ve Cudeck, 1993; Byrne, 2010; Hu ve Bentler, 1999; Kline, 2011; Tanaka ve Huba, 1985). Test edilen tek faktörlü model şekil 1'de gösterilmiștir. Bu sonuçlar dikkate alındığında temel hipotezin doğrulandığı görülmektedir. Aynı zamanda, kendini toparlamadan, yaşam doyumuna; kendini toparlamadan motivasyona; motivasyondan akademik ertelemeye; akademik özdeşleşmeden akademik ertelemeye giden yollar .01 düzeyinde anlamlı oldukları görülmektedir. Diğer yolların ise anlamlı olmadıkları görünmektedir. Modelde yer alan bağımsız değişkenlerin bağımlı değişkenler üzerindeki doğrudan, dolaylı ve toplam etkilerine ilişkin bulgular aşağıda verilmiştir. 
Tablo 3

Bağımsız Değișkenlerin, Bă̆ımlı Değişkenler Üzerindeki, Doğrudan, Dolaylı ve Toplam Etkileri

\begin{tabular}{|c|c|c|c|c|c|c|c|c|c|c|c|c|}
\hline & \multicolumn{3}{|c|}{$\begin{array}{c}\text { Kendini } \\
\text { Toparlama }\end{array}$} & \multicolumn{3}{|c|}{$\begin{array}{l}\text { Yaşam } \\
\text { Doyumu }\end{array}$} & \multicolumn{3}{|c|}{ Motivasyon } & \multicolumn{3}{|c|}{$\begin{array}{c}\text { Akademik } \\
\text { Özdeşleşme }\end{array}$} \\
\hline & 1 & 2 & 3 & 1 & 2 & 3 & 1 & 2 & 3 & 1 & 2 & 3 \\
\hline Yaşam Doyumu & .42 & - & .42 & - & - & - & - & - & - & - & - & - \\
\hline Motivasyon & .46 & .03 & .50 & .08 & - & .08 & - & - & - & - & - & - \\
\hline $\begin{array}{l}\text { Akademik } \\
\text { Özdeşleşme }\end{array}$ & .09 & .03 & .11 & .06 & - & .06 & - & - & - & - & - & - \\
\hline $\begin{array}{l}\text { Akademik } \\
\text { Erteleme }\end{array}$ & - & -.26 & -.26 & -.11 & -.04 & -.15 & -.40 & - & -.40 & -.18 & - & -.18 \\
\hline
\end{tabular}

1: Doğrudan Etkiler; 2: Dolaylı Etkiler; 3: Toplam Etkiler

Akademik ertelemeyi açıklamaya çalışan model testinde elde edilen değerler incelendiğinde, motivasyon değişkeninin akademik ertelemeye doğrudan, anlamlı ve negatif yönlü etki yaptığı görülmektedir ( $t=-5.74, p<.01)$. Motivasyonun akademik ertelemeye doğrudan etki değeri $\beta=-$ .40 olduğu görülmektedir. Buna göre, öğrencilerin motivasyonun artması ile birlikte, akademik erteleme davranışlarının azaldığını söylenebilir. Tablo incelendiğinde, akademik özdeşleşme değişkeninin akademik ertelemeye doğrudan, anlamlı ve negatif yönlü etki yaptığı görülmektedir ( $\mathrm{t}=--2,619, \mathrm{p}<05)$. Akademik özdeşlemenin, akademik ertelemeye doğrudan etki değeri $\beta=-.18$ olduğu görülmektedir. Buna göre düşünüldüğünde, akademik özdeşlemenin artması ile birlikte, akademik erteleme davranışlarının azaldığını söylemek mümkündür. Araştırma sonuçları incelendiğinde, yaşam doyumunun akademik ertelemeye doğrudan anlamlı bir etkisinin olmadığı $(\mathrm{t}=-1,503, \mathrm{p}>\mathrm{05})$ görülmektedir. Yaşam doyumunun, akademik ertelemeye doğrudan etkisinin $\beta=-.11$ olduğu bulunmuştur. Fakat, yaşam doyumu, akademik özdeşleşme ve motivasyon değişkenleriyle birlikte akademik ertelemeye toplamda $\beta=-.15$ etki yaptığı görülmektedir. Yani yaşam doyumu, akademik özdeşleşme ve motivasyonla birlikte akademik ertelemeye anlamlı ve negatif yönlü katkı sağladığını söylemek mümkündür. Araştırma sonuçları incelendiğinde, kendini toparlama gücünün akademik ertelemeyi yaşam doyumu, motivasyon ve akademik özdeşleşme üzerinden toplamda $\beta=-.26$ etki yaptığı görülmektedir. Buna göre düşünüldüğünde, öğrencilerin kendini toparlama gücünün artması, akademik ertelemeyi düşürdüğünü ve bu anlamda akademik ertelemenin yordanmasına önemli katkılarının olduğu söylenebilir.

\section{Tartışma ve Sonuç}

Araştırma sonucunda, sınıf tekrarı yapan öğrencilerin akademik erteleme davranışının, kendini toparlama, yaşam doyumu, motivasyon ve akademik özdeşleşme ile birlikte bir model kapsamında açıklandığı görülmektedir. $\mathrm{Bu}$ bağlamda temel hipotezin doğrulandığı görülmektedir. Araştırma sonucunda, akademik erteleme davranışını, kendini toparlama gücü dışındaki diğer değişkenlerin yordadığı görülmektedir. Kendini toparlama gücünün ise toplamda ve diğer aracı değişkenlere yaptığı katkıyla birlikte akademik ertelemeyi yordadığı görülmüştür. 
Akademik ertelemeyi açıklamaya çalışan model testinde elde edilen değerler incelendiğinde, motivasyon değişkeninin akademik ertelemeye doğrudan, anlamlı ve negatif yönlü etki yaptığı görülmektedir. Motivasyonun akademik ertelemeye doğrudan etki değeri $\beta=-.40$ olduğu görülmektedir. İlgili literatür incelendiğinde, motivasyon ya da güdülenmenin akademik ertelemeyi açıklamada araştırma sonuçlarına benzer bulgulara rastlanmıştır )Akbay, 2009; Klassen ve diğ.,2008; Lekich, 2006; Lee, 2005). Öğrencilerin akademik sorumluluklarına ilgi, merak duyması ve bu bağlamda çaba göstermesi, akademik sorumlulukları yerine getirmede hızlı davranmalarına neden olabilir. Araştırma sonuçları incelendiğinde, yaşam doyumunun akademik ertelemeye doğrudan anlamlı bir etkisinin olmadığı $(t=-1,503, p>05)$ görülmektedir. Yaşam doyumunun, akademik ertelemeye doğrudan etkisinin $\beta=-.11$ olduğu bulunmuştur. İlgili literatür incelendiğinde araştırma bulgularının tam tersi durumla karşılaşıldığ görülmektedir. Binder (2000) ve Savithri (2014) öğrencilerin yaşamından almış oldukları doyum ile akademik erteleme arasında negatif yönlü bir korelasyon olduğunu, aynı zamanda yaşam doyumunun akademik ertelemeyi yordamada negatif yönlü ve anlamlı bir etkisinin olduğunu ifade etmektedirler. Yapılan araştırmada, korelasyon yeterliliği incelendiğinde, yaşam doyumu ile akademik erteleme arasında negatif yönlü anlamlı ilişki bulunmuştur. Fakat değişkenler modele girdiğinde, sınıf tekrarı yapan öğrencilerin erteleme davranışını, motivasyon, yılmazlık ya da akademik özdeşleşme gibi daha önemli değişkenlerin açıklama düzeyleri daha baskın olmuş olabilir. Yani sınıf tekrarı yapan öğrencilerin erteleme yapmasındaki temel nedenler arasında yaşam doyumundan daha öncelikli değişkenler olabilir. Araştırma sonucunda, akademik özdeşleşme değişkeninin akademik ertelemeye doğrudan, anlamlı ve negatif yönlü etki yaptığı görülmektedir. Buna göre düşünüldüğünde, akademik özdeşlemenin artması ile birlikte, akademik erteleme davranışlarının azaldığını söylemek mümkündür. İlgili literatür incelendiğinde, araştırma bulgusunun desteklendiği görülmektedir.

Balkıs, Duru ve Buluş (2009)'nun, akademik erteleme eğiliminin-akademik başarı ile ilişkisinde, öğrencilerin akademik özdeşleşme ve kişisel sorumluluk düzeylerinin dolaylı rollerini araştırdığı bir araştırmada, akademik erteleme ile özdeşleşme arasında negatif yönlü bir ilişki bulunmuştur. Öğrencilerin, akademik görevleri kendi benliğini güçlendirmek için aracı görmesi, öğrenme motivasyonunu olumlu etkileyebilir. Bu durumda erteleme davranışı azalabilir. Araştırma sonuçları incelendiğinde, kendini toparlama gücünün akademik ertelemeyi yaşam doyumu, motivasyon ve akademik özdeşleşme üzerinden toplamda $\beta=-.26$ etki yaptığı görülmektedir. ilgili literatür incelendiğinde, araştırma bulgularının desteklediği görülmektedir (Öksüz ve Güven, 2014) .Buna göre düşünüldüğünde, öğrencilerin kendini toparlama gücünün artması, akademik ertelemeyi düşürdügünü ve bu anlamda akademik ertelemenin yordanmasına önemli katkılarının olduğu söylenebilir. Yukarıdaki sonuçlar dikkate alındığında, araştırma hipotezlerinin çoğunluğunun doğrulandığı, fakat bir tanesinin doğrulanmadığı söylenebilir. Doğrulanmayan hipotez, "akademik erteleme davranışı; yaşam doyumu, motivasyon ve akademik özdeșleşme değişkenleri tarafından doğrudan etkilerle yordanmaktadır" hipotezidir. Araştırma sonucunda, yaşam doyumunun akademik ertelemeyi doğrudan etki değerinin yordayıcı olmadığı yukarıda belirtilmiştir. Bunun dıșında, araştırma hipotezleri doğrulanmıştır. 


\section{Kaynaklar}

Aitken, M. E. (1982). A personality profile of the college student procrastinator. University of Pittsburgh: Pro Quest Dissertations and Theses. Retrieved March 21, 2012 fromhttp://search.proquest. com/docview/303242158?accountid=11054.

Allen, L. R. ve Hurtes, K. (1999). Making an Impact. Parks ve Recreation, 34 (11)

Balkıs, M. (2006). Öğretmen adaylarının davranışlarındaki erteleme eğiliminin, karar verme tarzları ile ilişskisi. Yayınlanmamış Doktora Tezi. İzmir: Dokuz Eylül Üniversitesi, Eğitim Bilimleri Enstitüsü.

Balkıs, M. (2007). Üniversite öğrencilerinin davranışlarındaki erteleme eğiliminin, karar verme stilleri ile ilișkisi. Pamukkale Üniversitesi Eğitim Fakültesi Dergisi. 1, (21), 67-83.

Balkıs, M. ve Duru, E. (2009). Akademik erteleme davranışının öğretmen adayları arasındaki yaygınlığı, demografik özellikler ve bireysel tercihlerle ilişkisi. Eğitimde Kuram ve Uygulama, 5(1), 18-32.

Balkıs, M., Duru, E., Buluş, M. ve Duru, S. (2009). Akademik erteleme eğilimi-akademik başarı ilişsisinde akademik özdeşleş̧me ve kişisel sorumluluğun rolü. 18. Ulusal Eğitim Bilimleri Kurultayı, İzmir

Binder, K. (2000). The effect of an academic procrastination treatment on student procrastination and subjective well-being. Unpublished MA, Carleton University, Canada.

Bollen, K. A. (1989). A new incremental fit index for general structural equation models. Sociological Methods \& Research, 17(3), 303-316.

Bozanoğlu, D. (2004). Akademik güdülenme ölçeği: Geliştirilmesi, geçerliği ve güvenirliği. Ankara Üniversitesi Eğitim Bilimleri Fakültesi Dergisi, 37, 83-98.

Browne, M. W. ve Cudeck, R. (1993). Alternative ways of assessing model fit. Sage Focus Editions, 154, 136-136.

Burka, J. B., ve Yuen, L. M. (1983). Procrastination: Why you do it, what to do about it. Reading, MA: Addison-Wesley.

Byrne, B. M. (2010). Structural equation modeling with AMOS: Basic concepts, applications, and programming (2nd ed.). New York: Taylor \& Francis.

Clark, J. L., ve Hill, O. W. (1994). Academic procrastination among African- American college students. Psychological Reports, 75, 931-936.

Çokluk, Ö., Şekercioğlu, G. ve Büyüköztürk, Ş.(2012). Sosyal bilimler için çok değişkenli SPSS ve LISREL uygulamaları. Ankara: PegemA Yayıncıllk.

Diener, E., Emmons, R.A., Larsen, R.J., ve Griffin, S. (1985). The Satisfaction with Life Scale. Journal of Personality Assessment, 49, 1-5.

Farran, B. (2004). Predictors of academic procrastination in college students. Unpublished Doctoral Dissertation. Fordham University. ABD.

Ferrari, J.R., Johnson, J.L. ve McCown, W. (1995). Procrastination and task avoidance: theory, research and treatment. New York: Plenum. 
Fraenkel, J.R. ve Norman, E.W. (2006). How to design and evaluate research in education. New York: Mc Graw-Hill.

Gall, D. M., Borg, R. W. ve Gall, P. J. (1996). Educational research: An introduction (6th Edition). USA: Longman Publishers.

Hill, M., Hill, D., Chabot, A. ve Barral, J. (1978). A survey of college faculty and student procrastination. College Students Personal Journal, 12, 256-262.

Hu, L. T. ve Bentler, P. M. (1999). Cutoff criteria for fit indexes in covariance structure analysis: Conventional criteria versus new alternatives. Structural Equation Modeling: A Multidisciplinary Journal, 6(1), 1-55.

Kandemir, M. (2010). Akademik erteleme davranışııı açıklayıcı bir model. Yayımlanmamış Doktora Tezi, Gazi Üniversitesi, Eğitim Bilimleri Enstitüsü, Ankara.

Kandemir, M. (2012). Öğrencilerin akademik erteleme davranışlarının, kaygı, başarısızlık korkusu, benlik ve başarı amaçlarıyla açıllanması. Pegem Eğitim ve Öğretim., 2, 4: 81-88.

Karasar, N. (2002). Bilimsel Araştırma Yöntemi. Ankara: Nobel Yayın Dağıtım.

Klassen, R., Krawchuk, L. ve Rajani, S. (2007). Academic procrastination of undergraduates: Low self-efficacy to self-regulate predicts higher levels of procrastination. Contemporary Educational Psychology. 33, 915-931.

Kline, R. B. (2005). Principles and practice of structural equation modeling (2nd ed.). New York: Guilford Press.

Kline, R.B. (2011), Principles and Practice of Structural Equation Modeling (3nd Edition ed.). New York: The GuilfordPress.

Knaus, W.J. (1998). Do it now! Break the procrastination habit. New York: John WileyveSons, Inc.

Köker S (1991) Normal ve sorunlu ergenlerin yaşam doyumu düzeylerinin karşılaştırılması. Yayınlanmamış yüksek lisans tezi. A. Ü. Sosyal Bilimler Enstitüsü, Ankara.

Lekick, N.(2006). The relationship between academic motivation, self esteem and academic procrastination in college students. Unpuplished master"s thesis, Truman State University. Kirksville, Missouri.

Maruyama,G. M. (1998). Basics of Structural Equation Modeling,Thousand Oaks,CA: Sage.

Osborne,J.W.(1997). Race and academic disidentification. Journal of Educationla Psychology, 89, 728-735

Pavrot, W., ve Diener, E. (1993). Review of the satisfaction with life scale. Psychological Assessment, 5, 164-172.

Rothblum, E. D., Solomon, L. J. ve Murakami, J. (1986). Affective, cognitive, and behavioral differences between high and low procrastinators. Journal of Counseling Psychology, 33(4), 387-394.

Savithri , J.J. (2014). Interactive effect of academic procrastination and academic performance on life satisfaction. International Journal of Science and Research (IJSR). 3 (3). 377-381. 
Senecal ,C., Koestner, R., \& Vallerand, R. J. (1995). Self-regulation and academic procrastination. Journal of Social Psychology, 135(1), 607-619.

Schumacker, R. E. ve Lomax, R. G. (2010). A beginner's guide to structural equation modeling. New York: Routledge

Solomon, L. J. ve Rothblum, E. D. (1984). Academic procrastination: Frequency and cognitivebehavioral correlates. Journal of Counseling Psychology, 31, 503-509.

Tabachnick, B. G. ve Fidell, L. S. (2001). Using multivariate statistics (4th ed.). Needham Heights, MA: Allyn \& Bacon.

Tanaka, J. S. ve Huba, G. J. (1985). A fit index for covariance structure models under arbitrary GLS estimation. British Journal of Mathematical and Statistical Psychology, 38(2), 197-201.

Tice, D. M. ve Baumeister, R. F. (1997). Longitudinal study of procrastination, performance, stress, and health: The costs and benefits of dawdling. Psychological Science. 8, 454-458.

Terzi, Ş. (2006). Kendini toparlama gücü ölçeğinin uyarlanması: Geçerlik ve güvenirlik çalışmaları. Türk Psikolojik Danışma ve Rehberlik Dergisi, 3(26), 77-86.

Veenhoven, R. (1996). The study of life satisfaction. In: W. E. Saris, R. Veenhoven, A. C. Scherpenzeel, \& B. Bunting (Eds). A comparative study of satisfaction with life in Europe. Budapest: Eötvös University Pres.

Öksüz, Y. ve Güven, E. (2014). The relationship between psychological resilience and procrastination levels of teacher candidates. Procedia -Social and Behavioral Sciences, $116,3189-3193$ 


\section{Extended Summary}

\section{Aim}

Class repetition which is one of the key factors affecting the educational life span of students is an important phenomenon for education system. Experiencing class repetition by a student can lead to undesirable experiences such as having the failure identity, following the life retarded for at least one year according to his peers, and the inability to adapt to the changing situation. Rothblum, Solomon and Murakami (1986) defines this behaviour as consistently or occasionally procrastination of academic duties such as preparing for examinations or doing homework. The academic procrastination behaviour that students make prevalently might be shown among important variables that may cause students to fall into this phenomenon by experiencing failure. Self-efficacy, personality, motivation, life satisfaction, time management, and control focus appear to be important variables in the research of causality in academic delay (Kandemir, 2012). In researches devoted to explain the behaviour of academic procrastination, variables of self-recovery, life satisfaction, motivation and academic motivation are important as mentioned above. When the literature is examined, there is no researches related to explaining to what extent the academic procrastination behaviour of the students who perform the class repetition, namely the students with the academic risk group, with or without variables of self-recovery, life satisfaction, motivation, academic motivation. Considered in this context, it is thought that the value added of this research is important. The fact that the study is carried out with a model test suggests that these variables are different from the studies in which these variables used together. In accordance with above mentioned data, the purpose of the research is to test the academic procrastination behaviours of 1 st and 2nd grade high school students within the scope of a model with variables of self-recovery, life satisfaction, academic identification and motivation.

\section{Method}

The research that used the causal comparative method were carried out on 234 high school students who made a class repetition in the academic year of 2013-2014. 92 (40\%) of the students in the research group were male and $140(60 \%)$ of them were female students. As the tool for data collecting, Academic Procrastination Scale developed by Aitken (1982) and adopted into Turkish by Balkıs (2007), Self-Recovery Power Scale developed by Terzi (2006), Life Satisfaction Scale developed by Diener (2004) and adopted into Turkish by Köker (1991), Academic Motivation Scale developed by Bozanoğlu (2004), Academic Identification Scale developed by Balkıs, Duru and Buluş (2009) are used in the research. In the study, AMOS 16 statistical program was used to analyse the path and to test this model. Path models have an understanding of using regression analysis and correlation coefficients to further contribute to the modelling of more complex relationships between observed variables. That of Maruyama (1998) is also known as an analysis method that shows the partial effects of independent variables on path analysis with standardized regression coefficients. 


\section{Findings}

According to the research results, received fit coefficients related to final model are resulted highly above of acceptable limits. That the NFI, CFI, IFI and TLI values are above .90 indicates that this model adjusts well. Chi-square value was found as $\left(\mathrm{X}^{2} / \mathrm{sd}=3.33 / 2\right) 1.67$ and RMSEA was found as .048. Considering these coefficients and fit indexes, it is understood that model has the fit values in desired level (Bollen, 1989; Browne and Cudeck, 1993; Byrne, 2010; Hu and Bentler, 1999; Kline, 2011; Tanaka and Huba, 1985). Tested one-factor model is shown in Figure-1. When these results are taken into consideration it is seen that the basic hypothesis is confirmed. At the same time, it is seen that paths from self-recovery to life satisfaction, selfrecovery to motivation, motivation to academic procrastination and academic identification to academic procrastination are meaningful at .01 level. On the other hand, other paths are not seen meaningful. Also, motivation variable affects academic procrastination in a direct, meaningful and negative ways $(\mathrm{t}=-5.74, \mathrm{p}<.01)$. Motivation's direct affect value to the academic procrastination is found as $\beta=-.40$. Accordingly, it can be said that students' academic procrastination behaviours decrease along with improved motivation.

\section{Discussions, Results and Suggestions \\ 0*}

As a result of the study, it was found that the academic procrastination behaviours of the students who had made the class repetition are explained within a scope of a model along with self-recovery, life satisfaction, motivation and academic identification. Within this context, it is seen that the basic hypothesis is confirmed. As a result of the research, other variables except self-recovery power predicts academic procrastination behaviour. Self-recovery power on the other hand predicts academic procrastination with contribution to other intermediary variables and to total. Motivation variable affects academic procrastination directly, meaningfully and negatively when values obtained in the model test trying to explain academic procrastination are examined. Motivation's direct affect value to the academic procrastination is found as $\beta=-$ .40. When the related literature is examined, findings like the results of research on motivation or academic delay are found (Akbay, 2009, Klassen et al., 2008; Lekich, 2006; Lee, 2005). Student's being interest in and curious about their academic responsibilities and show some effort within this context may cause them to be quick to fulfil their academic responsibilities. Life satisfaction does not affect academic procrastination directly in a significant way when results of the research are examined $(t=-1,503, p>05)$. It is found that life satisfaction's direct effect to the academic procrastination is $\beta=-.11$. When the related literature is examined, it is seen that the opposite situation of the research findings is encountered. Binder (2000) and Savithri (2014) states that there are negative correlations between students' satisfaction with their life and academic procrastination, while at the same time the life satisfaction is a negative and significant effect on predicting academic procrastination. When result of the research are taken into consideration, it can be said that all of the research hypothesis except one are validated. Invalidated hypothesis is "academic Procrastination behaviour is predicted by life satisfaction, motivation and academic identification variables with direct effect". As a result of the research result, it is above mentioned that life satisfaction has no predictive direct effect value on academic procrastination. Apart from that, research hypothesis are confirmed. 